\title{
Phylogeny of Japanese Stag Beetles (Coleoptera: Lucanidae) Inferred from 16S mtrRNA Gene Sequences, with Reference to the Evolution of Sexual Dimorphism of Mandibles
}

\author{
Tadatsugu Hosoya ${ }^{1,2}$ and Kunio Araya ${ }^{2 *}$ \\ ${ }^{1}$ Graduate School of Science, Kyoto University, Kitashirakawa, Sakyo, Kyoto 606-8502, Japan \\ ${ }^{2}$ Graduate School of Social and Cultural Studies, Kyushu University, 4-2-1 \\ Ropponmatsu, Chuo, Fukuoka 810-8560, Japan
}

\begin{abstract}
As a first step in reconstructing the phylogeny of world stag beetles (Coleoptera: Lucanidae), phylogenetic relationships among the major members of Japanese stag beetles were explored by analyzing a sequence of 1030 nucleotides from the mitochondrial 16S ribosomal RNA (16S rRNA) gene. A total of 20 species and three additional subspecies representing 13 genera were examined to provide basic information on the phylogeny of world Lucanidae. The resultant phylogenetic tree indicates that the family Lucanidae is monophyletic, and contains two major lineages: one consists of the genera Platycerus, Aesalus, Ceruchus, and Nicagus, and the other includes Dorcus, Rhaetulus, Prosopocoilus, Aegus, Neolucanus, Prismognathus, Lucanus, Figulus, and Nigidius. Generic members of the latter lineage are further divided into the following four sublineages: i) Figulus and Nigidius; ii) Prismognathus and Lucanus; iii) Aegus and Neolucanus; and iv) Dorcus, Rhaetulus, and Prosopocoilus. These molecular phylogenetic relationships are used as a basis for a preliminary exploration of the evolution of sexual dimorphism in the shape of the mandible. The results of this investigation suggest that strong sexual dimorphism with well-developed mandibles in males evolved independently at least twice, once in the genus Aegus and once in the ancestor of the Lucanus-Prismognathus and Dorcus-Rhaetulus-Prosopocoilus clades. Alternatively, it is possible that sexual dimorphism of mandibles has undergone secondary loss in the genera Figulus and Nigidius.
\end{abstract}

Key words: Lucanidae, Coleoptera, molecular phylogeny, $16 \mathrm{~S}$ rRNA, mitochondrial DNA, evolution, sexual dimorphism, mandibles

\section{INTRODUCTION}

The family Lucanidae (stag beetles), consisting of about 1000 species, is widely distributed around the world and is particularly abundant in the Oriental region (Didier and Séguy, 1953; Benesh, 1960; Maes, 1992; Mizunuma and Nagai, 1994; Krajcik, 2001). Stag beetles have received wide attention from scientists because of their remarkable sexual dimorphism and the individual variation exhibited by males, especially in the shape of the mandibles (e.g., Inukai, 1924; Huxley, 1931; Arrow, 1937, 1950; Otte and Stayman, 1979; Sakaino, 1987, 1988; Kawano, 1997, 2000; Tatsuta et al., 2001).

Systematically, however, controversy has surrounded the considerable changes affecting the taxonomic status of many taxa in this family and the higher classification levels,

\footnotetext{
${ }^{*}$ Corresponding author. Phone: +81-92-726-4636;

Fax : +81-92-726-4644;

E-mail: arayarcb@mbox.nc.kyushu-u.ac.jp
}

such as tribes and subfamilies (Didier and Séguy, 1953; Benesh, 1960; Kikuta, 1986; Maes, 1992; Mizunuma and Nagai, 1994; Krajcik, 2001), as shown in Table 1. Additionally, only a few comparative studies, such as Sharp and Muir (1912) and Houlbert (1915), based on adult morphology have demonstrated hypothetical affinities of several subfamilies in the family Lucanidae, but the results of these studies did not agree with one another. This suggests a difficulty in selecting morphological characters for a phylogenetic analysis of the family Lucanidae.

A phylogenetic analysis based on molecular data is expected to significantly improve the resolution of the phylogeny of the family Lucanidae. Several studies have utilized various types of molecular data to infer phylogenetic relationships of lucanid taxa, including allozyme electrophoresis (Igarashi et al., 1994; Matsuoka et al., 1998; Matsuoka and Hosoya, 2003), random amplified polymorphic DNA (Hosoya et al., 2002), and nucleotide sequences of the mitochondrial cytochrome c oxidase subunit I (COI) (Trewick, 2000; 
Table 1. List of lucanid beetles classification according to different authors used in this study.

\begin{tabular}{|c|c|c|c|c|}
\hline $\begin{array}{l}\text { Species and subspecies } \\
\text { (Mizunuma and Nagai, 1994) }\end{array}$ & $\begin{array}{l}\text { Didier and } \\
\text { Séguy (1953) }\end{array}$ & $\begin{array}{l}\text { Benesh (1960) } \\
\text { Krajcik (2001) }\end{array}$ & Kikuta (1986) & Maes (1992) \\
\hline Dorcus curvidens binodulosus * & Dorcinae & Dorcinae & Lucaninae & Dorcinae \\
\hline \multicolumn{5}{|l|}{ Dorcus titanus pilifer } \\
\hline \multicolumn{5}{|l|}{ Dorcus titanus okinawanus } \\
\hline \multicolumn{5}{|l|}{ Dorcus rectus rectus } \\
\hline Rhaetulus recticornis & Lucaninae & & & \\
\hline Prosopocoilus inclinatus inclinatus & Cladognathinae & & & \\
\hline \multicolumn{5}{|l|}{ Prosopocoilus pseudodissimilis } \\
\hline \multicolumn{5}{|l|}{ Prismognathus angularis angularis } \\
\hline \multicolumn{5}{|l|}{ Prismognathus dauricus } \\
\hline Aegus laevicollis subnitidus & Dorcinae & & & \\
\hline Lucanus maculifemoratus maculifemoratus & Lucaninae & Lucaninae & & Lucaninae \\
\hline \multicolumn{5}{|l|}{ Lucanus ferriei } \\
\hline Neolucanus protogenetivus protogenetivus & Chalcodinae & & & Odontolabinae \\
\hline \multicolumn{5}{|l|}{ Neolucanus protogenetivus hamaii } \\
\hline Platycerus delicatulus delicatulus & Dorcinae & Aesalinae & & Platycerinae \\
\hline \multicolumn{5}{|l|}{ Platycerus acuticollis acuticollis } \\
\hline Figulus binodulus & Figulinae & Figulinae & & Figulinae \\
\hline \multicolumn{5}{|l|}{ Figulus boninensis } \\
\hline \multicolumn{5}{|l|}{ Nigidius lewisi } \\
\hline Ceruchus lignarius lignarius & Aesalinae & Aesalinae & Ceruchinae & Syndesinae \\
\hline \multicolumn{5}{|l|}{ Ceruchus lignarius monticola } \\
\hline Aesalus asiaticus asiaticus & & & Aesalinae & Aesalinae \\
\hline Nicagus japonicus & & & Trogidae $^{\star \star}$ & \\
\hline
\end{tabular}

* We treated Dorcus curvidens binodulus in the catalogue of Mizunuma and Nagai (1994) as followed by Dorcus curvidens binodulosus followed by lkeda and Nishimura (1995).

** Kikuta (1986) treated that Nicagus did not include into the family Lucanidae, including into the family Trogidae.

Hosoya et al., 2003) and $16 \mathrm{~S}$ ribosomal RNA (rRNA) genes (Hosoya et al., 2001). However, these studies at most dealt with several taxa within a single genus or a few closely related genera, but did not examine phylogenetic relationships among the higher groups of the family Lucanidae, such as tribes and subfamilies.

In the present study, we investigated the phylogenetic relationships among Japanese stag beetles based on nucleotide sequences of the mitochondrial 16S rRNA gene as a first step in reconstructing the phylogeny of world lucanid beetles. This gene was chosen because it has provided phylogenetic resolution among genera, tribes, and/or subfamilies of other insects (e.g., Fang et al., 1993; Dowton and Austin, 1994; Kambhampati et al., 1996; Han and McPheron, 1997; Kambhampati et al., 2000). Although the higher classification of the family Lucanidae has varied considerably among different studies, the Japanese lucanid beetles include most of the major lineages of the family outlined by any of the competing classification schemes. The Japanese species represent at least half the number of subfamilies proposed thus far, and six of the ten subfamilies proposed by Didier and Séguy (1953), four of the eight suggested by Benesh (1960), three of the six outlined by Kikuta (1986), seven of the nine put forward by Maes (1992), and four of the eight recognized by Krajcik (2001).

We also discuss evolutionary aspects of sexual dimorphism of the shape of the mandible within this beetle family on the basis of the phylogenetic trees we obtained.

\section{MATERIALS AND METHODS}

Insects

The taxa used in this study are listed in Table 1, which also shows differences among higher classification systems of the family Lucanidae. We mainly followed the taxonomic treatment of Mizunuma and Nagai (1994). A total of 20 species and three additional subspecies representing 13 genera were collected from Japan and subjected to DNA analysis (Table 2; Fig. 1). For some genera, such as Dorcus, which include many Japanese species, we selected a few representative species from each genus, since our main purpose here was to reconstruct phylogenetic relationships among the genera of Japanese stag beetles. As for the three additional subspecies, we selected two different subspecies pairs to represent most of the major zoogeographic distribution patterns. 
Table 2. List of taxa, sampling places and sequence accession numbers of lucanid beetles used in this study.

\begin{tabular}{|c|c|c|c|}
\hline Family & $\begin{array}{l}\text { Species and subspecies } \\
\text { (Mizunuma and Nagai, 1994) }\end{array}$ & Sampling place & $\begin{array}{l}\text { Accession } \\
\text { numbers }\end{array}$ \\
\hline \multirow[t]{23}{*}{ Lucanidae } & Dorcus curvidens binodulosus * & Yamanashi & AB178292 \\
\hline & Dorcus titanus pilifer & Kyoto Univ., Sakyo, Kyoto, Kyoto & AB178293 \\
\hline & Dorcus titanus okinawanus & Kunigami, Okinawa I., Okinawa & AB178294 \\
\hline & Dorcus rectus rectus & Meya dam, Nishimeya, Aomori & AB178295 \\
\hline & Rhaetulus recticornis & Amami I., Kagoshima & AB178296 \\
\hline & Prosopocoilus inclinatus inclinatus & Meya dam, Nishimeya, Aomori & AB178297 \\
\hline & Prosopocoilus pseudodissimilis & Ishigaki I., Okinawa & AB178298 \\
\hline & Prismognathus angularis angularis & Mt. Hikosan, Fukuoka & AB178299 \\
\hline & Prismognathus dauricus & Kamiagata, Tsushima, Nagasaki & $\mathrm{AB} 178300$ \\
\hline & Aegus laevicollis subnitidus & Kiikatsuura, Wakayama & AB178301 \\
\hline & Lucanus maculifemoratus maculifemoratus & Meya dam, Nishimeya, Aomori & AB178302 \\
\hline & Lucanus ferriei & Amami I., Kagoshima & $\mathrm{AB} 178303$ \\
\hline & Neolucanus protogenetivus protogenetivus & Mt. Yui, Amami I., Kagoshima & AB178304 \\
\hline & Neolucanus protogenetivus hamaii & Daisen, Uke I., Kagoshima & AB178305 \\
\hline & Platycerus delicatulus delicatulus & Tsuta, Towadako, Aomori & AB178306 \\
\hline & Platycerus acuticollis acuticollis & Mt. Nanba, Joetsu, Niigata & AB178307 \\
\hline & Figulus binodulus & Mt. Yoshida, Sakyo, Kyoto, Kyoto & AB178308 \\
\hline & Figulus boninensis & Mt. Tsutsuzi, Chichizima I., Ogasawara Is., Tokyo & AB178309 \\
\hline & Nigidius lewisi & Kiikatsuura, Wakayama & $\mathrm{AB} 178310$ \\
\hline & Ceruchus lignarius lignarius & Mt. Ozaki, Hiraka, Aomori & AB178311 \\
\hline & Ceruchus lignarius monticola & Mt. Fuji, Shizuoka & AB178312 \\
\hline & Aesalus asiaticus asiaticus & Ashu, Miyama, Kyoto & AB178313 \\
\hline & Nicagus japonicus & Oirase, Fukaura, Aomori & AB178314 \\
\hline Passalidae & Cylindrocaulus patalis & Mt. Ishizuchi, Ehime & AB178315 \\
\hline Trogidae & Trox uenoi & Mt. Yuwan, Amami I., Kagoshima & AB178316 \\
\hline Geotrupidae & Geotrupes laevistriatus & Katsurazawa dam, Mikasa, Hokkaido & AB178317 \\
\hline \multirow[t]{2}{*}{ Scarabaeidae } & Trypoxylus dichotomus septentrionalis & Hirosaki Univ., Hirosaki, Aomori & AB178318 \\
\hline & Heptophylla picea picea & Meya dam, Nishimeya, Aomori & AB178319 \\
\hline
\end{tabular}

* We treated Dorcus curvidens binodulus in the catalogue of Mizunuma and Nagai (1994) as followed by Dorcus curvidens binodulosus followed by lkeda and Nishimura (1995).

Neolucanus protogenetivus is distributed on the islands of the Ryukyu archipelago, and we selected two insular subspecies from neighboring islands ( Ne. p. protogenetivus and Ne. protogenetivus hamaii). Dorcus titanus is widely distributed in East and Southeast Asia, including many islands, and we selected a subspecies on the Japanese mainland ( $D$. titanus pilifer) and an insular subspecies of the Ryukyu archipelago (D. titanus okinawanus). Ceruchus lignarius is only found in mountainous areas of the Japanese mainland, and we selected two subspecies from the mountains of Honshu Island (Ce. I. lignarius and Ce. lignarius monticola). In some species of stag beetles, morphological differentiation has been reported between conspecific subspecies and/or populations (e.g., Benesh, 1960; Maes, 1992; Mizunuma and Nagai, 1994; Krajcik, 2001). However, in the present study, intraspecific and/or intra-subspecific samples were designated as a single operational taxonomic unit (OTU). This was because a previous study (Hosoya et al., 2001) showed that sequence divergence within a single species and/or subspecies was very low, with the relevant taxa exclusively forming the same clades with high bootstrap values. The nucleotide sequences of Dorcus rectus rectus, D. titanus pilifer, Ce. I. lignarius, and Ce. lignarius monticola were available from the published data of Hosoya et al. (2001).

The outgroups selected for the present analysis are given in Table 2 and include Cylindrocaulus patalis of the family Passalidae, Trox uenoi of the family Trogidae, Geotrupes laevistriatus of the family Geotrupidae, and Trypoxylus dichotomus septentrionalis and Heptophylla picea picea of the family Scarabaeidae, all of which belong to the superfamily Scarabaeoidea, as does the family Lucanidae (Browne and Scholtz, 1999).

\section{DNA extraction, amplification and sequencing}

Detailed methods concerning DNA extraction, amplification, and sequencing are described in Hosoya et al. (2001). We used specimens of adults, pupae, or larvae stored in $99.5 \%$ ethanol or at $-80^{\circ} \mathrm{C}$. A part of the mitochondrial $16 \mathrm{~S}$ rRNA gene was amplified by polymerase chain reaction (PCR) (Saiki et al., 1988) using seven primers: 16SA, 16SH, 16SB, 16SC, 16SD, 16SK (Hosoya et al., 2001) and 16SL (Fig. 2). Nucleotide sequences were determined for both strands with a Thermo Sequenase Cycle Sequencing Kit (USB, Cleveland, USA) and a LI-COR Model 4200 Automated DNA 

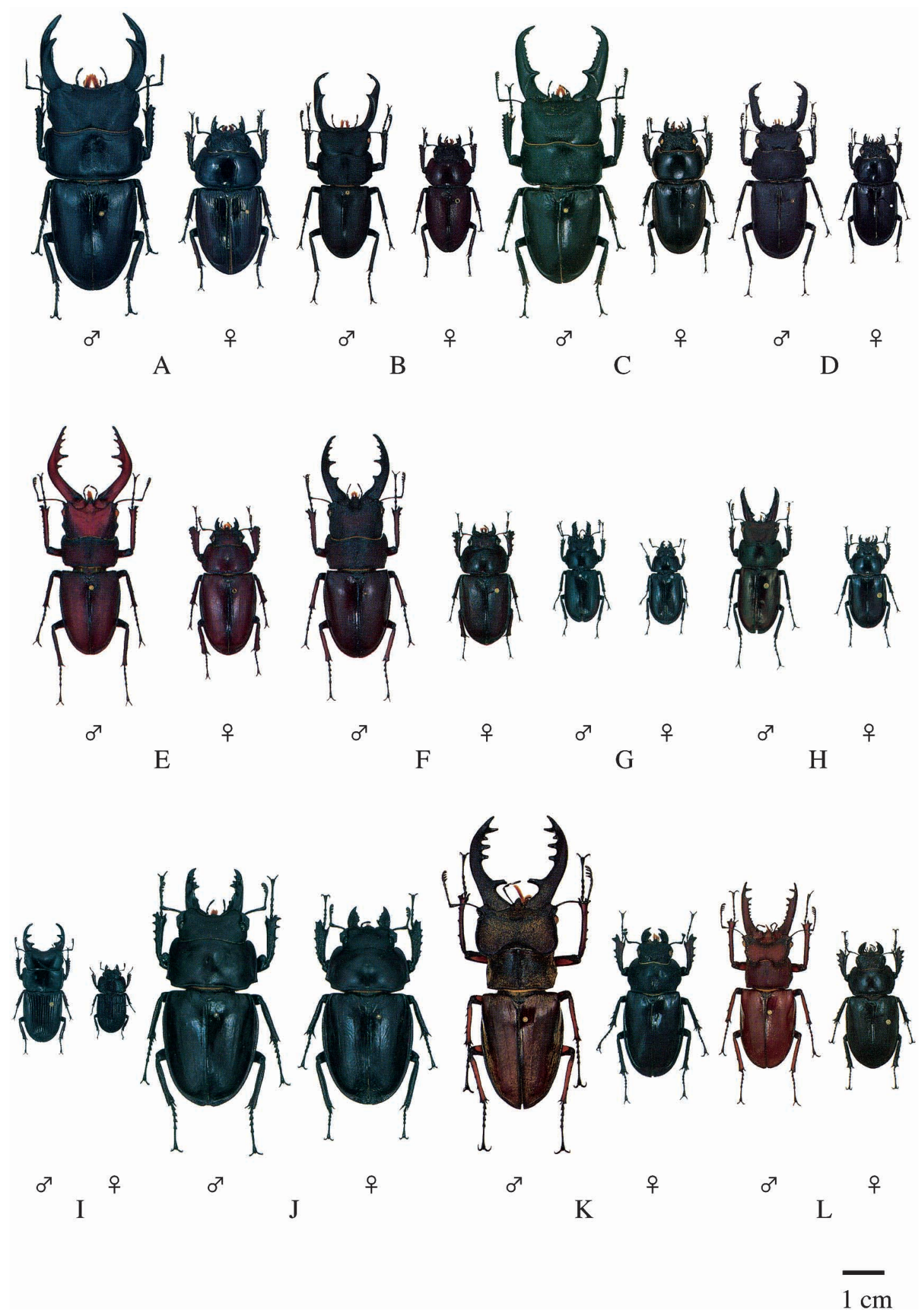

Fig. 1. To be continued. 


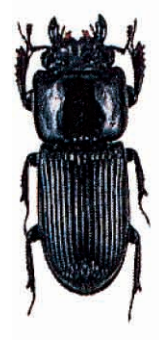

M

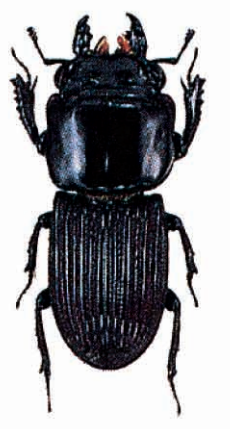

$\mathrm{N}$

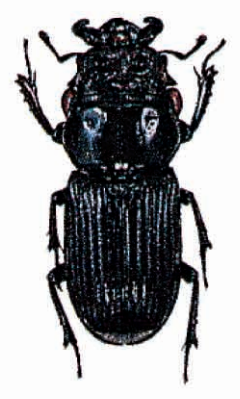

O

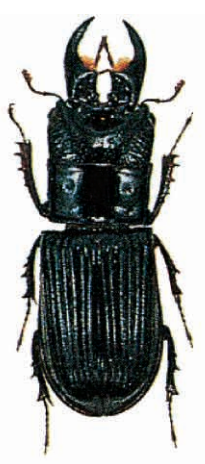

$\sigma^{x}$

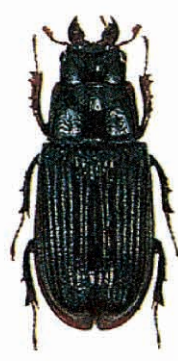

우

P

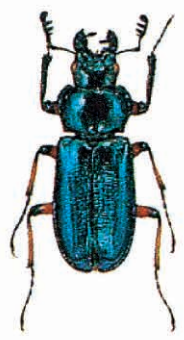

$\sigma^{x}$

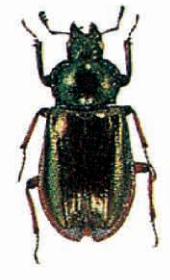

우

Q

우
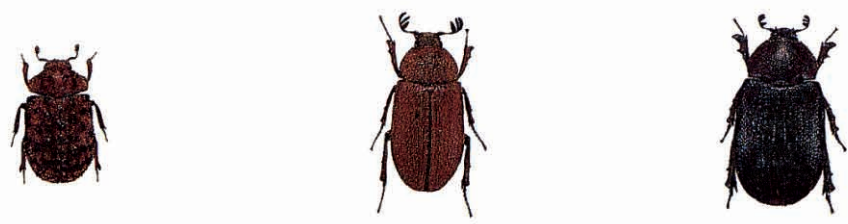

우

$0^{x}$

$\mathrm{T}$

\section{$1 \mathrm{~cm}$}

Fig. 1. Japanese lucanid species examined with respect to sexual dimorphism of mandible shape, grades of which are given in parentheses. A, Dorcus curvidens binodulosus (2); B, Dorcus rectus rectus (2); C, Dorcus titanus pilifer (2); D, Rhaetulus recticornis (2); E, Prosopocoilus inclinatus inclinatus (2); F, Prosopocoilus pseudodissimilis (2); G, Prismognathus angularis angularis (1); H, Prismognathus dauricus (2); I, Aegus laevicollis subnitidus (2); J, Neolucanus protogenetivus protogenetivus (1); K, Lucanus maculifemoratus maculifemoratus (2); L, Lucanus ferriei (2); M, Figulus binodulus (0); N, Figulus boninensis (0); O, Nigidius lewisi (0); P, Ceruchus lignarius lignarius (1); Q, Platycerus delicatulus delicatulus (1); R, Platycerus acticollis acticollis (1); S, Aesalus asiaticus asiaticus (1); T, Nicagus japonicus (0). Scale bars, $1 \mathrm{~cm}$.

Sequencer (LI-COR, Lincoln, USA) using 16SA, 16SH2, 16SB, $16 \mathrm{SC}$, and $16 \mathrm{SD}$ as sequencing primers (Fig. 2).

\section{Phylogenetic analysis}

Sequence data were aligned with web-based CLUSTAL W 1.8 (Thompson et al., 1994) software available through the DNA Data Bank of Japan (DDBJ), using default gap penalties. Gap sites were 


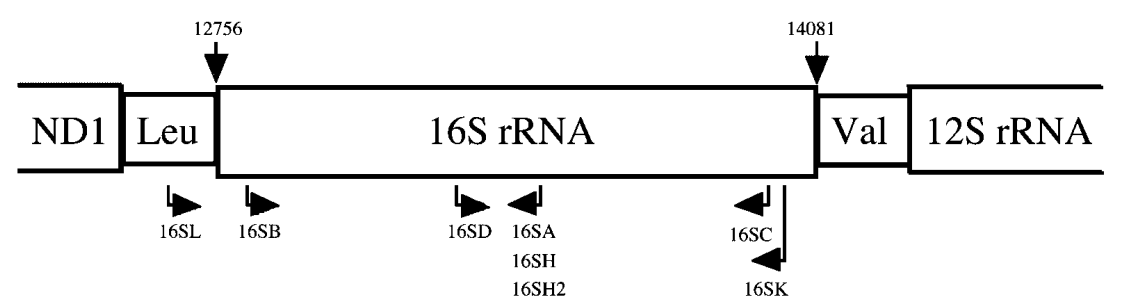

16SA (22bp : 13396-13427) 5'-CGC CTG TTT AAC AAA AAC ATG T-3' 16SB (22bp : 12866-12887) 5'-CCG GTT TGA ACT CAG ATC ATG T-3' 16SC (22bp : 13882-13903) 5'-TAC CTT GTG TAT CAG GGT TTA T-3' 16SD (22bp : 13311-13332) 5'-ATT ATG CTA CCT TTG CAC GGT C-3' 16SH (21bp : 13397-13427) 5'-TGC CTG TTT A(A/T)T AAA AAC ATG -3' 16SH2 (21bp : 13397-13427) 5'-TGC CTG TTT ATT AAA AAC ATG -3' 16SK (25bp : 13889-13913) 5'-TAA TTT ATT GTA CCT T(G/T)T GTA TCA G-3' 16SL (30bp : 12721-12750) 5' ATT CTA AAT (C/T)(C/T)A (A/T)(A/C/G/T)G CAC TA(A/T) TCT GCC AAA 3'

Fig. 2. Diagram of the mitochondrial $16 S$ rRNA gene and flanking tRNA, showing the positions of PCR and sequencing primers. Numbering is according to the Drosophila yakuba mitochondrial genome (Clary and Wolstenholme, 1985).

Table 3. Uncorrected p-distance (\%) for the $16 \mathrm{~S}$ rRNA gene sequences.

\begin{tabular}{|c|c|c|c|c|c|c|c|c|c|c|c|c|c|}
\hline & 1 & 2 & 3 & 4 & 5 & 6 & 7 & 8 & 9 & 10 & 11 & 12 & 13 \\
\hline 1. Dorcus curvidens binodulosus & - & & & & & & & & & & & & \\
\hline 2. D. titanus pilifer & 15.6 & - & & & & & & & & & & & \\
\hline 3. D. titanus okinawanus & 16.4 & 1.8 & - & & & & & & & & & & \\
\hline 4. D. r. rectus & 6.7 & 15.2 & 15.9 & - & & & & & & & & & \\
\hline 5. Rhaetulus recticornis & 19.9 & 20.0 & 20.0 & 18.8 & - & & & & & & & & \\
\hline 6. Prosopocoilus i. inclinatus & 18.5 & 19.6 & 19.7 & 17.9 & 14.1 & - & & & & & & & \\
\hline 7. Pro. pseudodissimilis & 17.7 & 19.9 & 19.9 & 17.4 & 14.9 & 6.6 & - & & & & & & \\
\hline 8. Prismognathus a. angularis & 21.5 & 21.6 & 21.7 & 21.9 & 23.3 & 21.7 & 21.6 & - & & & & & \\
\hline 9. Pri. dauricus & 23.0 & 22.4 & 22.5 & 22.9 & 23.8 & 22.6 & 22.4 & 8.6 & - & & & & \\
\hline 10. Lucanus $m$. maculifemoratus & 23.2 & 23.1 & 23.2 & 22.7 & 25.3 & 22.2 & 22.7 & 18.8 & 20.3 & - & & & \\
\hline 11. L. ferriei & 23.4 & 23.3 & 23.0 & 22.2 & 24.2 & 22.0 & 22.0 & 20.2 & 21.2 & 11.5 & - & & \\
\hline 12. Neolucanus $p$. protogenetivus & 22.2 & 21.8 & 22.0 & 22.7 & 22.2 & 22.9 & 23.6 & 21.8 & 23.3 & 25.8 & 24.2 & - & \\
\hline 13. Ne. protogenetivus hamaii & 22.2 & 21.7 & 21.9 & 22.9 & 22.2 & 22.6 & 23.4 & 22.0 & 23.7 & 26.0 & 24.4 & 0.6 & - \\
\hline 14. Aegus laevicollis subnitidus & 20.5 & 20.9 & 20.8 & 20.3 & 19.9 & 19.9 & 20.9 & 20.6 & 21.8 & 23.4 & 23.3 & 19.5 & 19.5 \\
\hline 15. Platycerus $d$. delicatulus & 23.6 & 23.7 & 23.8 & 23.4 & 26.0 & 24.9 & 24.9 & 26.4 & 25.6 & 26.5 & 27.3 & 26.1 & 26.1 \\
\hline 16. Pl. a. acticollis & 23.6 & 23.7 & 23.8 & 24.2 & 25.8 & 24.9 & 25.0 & 26.0 & 25.3 & 26.4 & 26.4 & 23.9 & 23.9 \\
\hline 17. Figulus binodulus & 24.3 & 25.2 & 25.7 & 24.0 & 24.4 & 21.6 & 23.2 & 24.6 & 25.7 & 24.5 & 27.0 & 25.0 & 24.7 \\
\hline 18. F. boninensis & 24.7 & 24.6 & 25.2 & 24.4 & 24.3 & 23.1 & 23.8 & 25.8 & 26.3 & 26.0 & 27.8 & 25.0 & 24.7 \\
\hline 19. Nigidius lewisi & 22.0 & 23.0 & 23.2 & 21.5 & 24.2 & 22.3 & 22.6 & 21.6 & 22.2 & 22.5 & 23.0 & 24.0 & 24.0 \\
\hline 20. Ceruchus I. lignarius & 23.9 & 23.9 & 24.2 & 24.3 & 25.0 & 23.1 & 24.2 & 24.7 & 24.6 & 26.8 & 26.0 & 25.3 & 25.6 \\
\hline 21. Ce. I. monticola & 23.7 & 22.7 & 22.9 & 23.7 & 24.9 & 22.5 & 23.6 & 25.1 & 24.9 & 26.7 & 25.9 & 24.5 & 24.7 \\
\hline 22. Aesalus a. asiaticus & 25.8 & 24.4 & 24.5 & 26.0 & 28.7 & 27.6 & 27.7 & 26.6 & 26.7 & 28.8 & 28.6 & 27.8 & 27.8 \\
\hline 23. Nicagus japonicus & 25.7 & 25.4 & 25.8 & 25.3 & 26.4 & 25.2 & 25.9 & 25.8 & 27.0 & 28.7 & 28.7 & 26.6 & 26.6 \\
\hline 24. Cylindrocaulus patalis & 28.6 & 27.6 & 27.4 & 27.9 & 29.7 & 27.0 & 26.6 & 26.0 & 26.7 & 28.5 & 27.8 & 27.4 & 27.7 \\
\hline 25. Trypoxylus dichotomus septentrionalis & 22.2 & 23.3 & 23.6 & 21.1 & 24.6 & 23.0 & 23.8 & 23.3 & 22.9 & 26.3 & 25.1 & 22.4 & 22.6 \\
\hline 26. Heptophylla p. picea & 23.7 & 24.9 & 24.9 & 23.6 & 26.1 & 24.4 & 24.5 & 24.0 & 25.2 & 26.7 & 26.7 & 24.3 & 24.5 \\
\hline 27. Trox uenoi & 23.6 & 23.4 & 24.0 & 23.3 & 24.3 & 21.5 & 23.1 & 23.0 & 22.9 & 25.1 & 25.6 & 23.7 & 24.2 \\
\hline 28. Geotrupes laevistriatus & 25.1 & 25.2 & 25.2 & 24.2 & 26.4 & 24.4 & 24.9 & 27.1 & 26.0 & 27.1 & 25.9 & 25.8 & 26.0 \\
\hline
\end{tabular}


excluded in all analyses. The data were also tested to determine if the resultant phylogenetic structure was significantly different from random by using the permutation tail probability (PTP) test (Faith and Cranston, 1991) with 10000 random matrices whilst randomizing all taxa by means of PAUP* $4.0 \mathrm{~b} 10$ (Swofford, 2002).

We examined the number of transitions ( $\mathrm{TI}$ ) and transversions (TV) against uncorrected p-distance to explore the possibility of saturated base substitutions. Saturation was judged to have taken place if the resulting scatter-plots were non-linear in shape (Maekawa et al., 1999; Maekawa and Matsumoto, 2000).

Sequence data were analyzed with the program MODELTEST (3.06) (Posada and Crandall, 1998), which uses hierarchical likelihood-ratio tests to determine the best-fit substitution model for the data. The optimal model defined by MODELTEST was then used to estimate maximum-likelihood (ML) distances for a neighbourjoining (NJ) analysis and to define parameters for a $M L$ analysis. The NJ method was implemented in PAUP* to infer the relationships among taxa based on the ML distance. For the ML and maximum-parsimony (MP) analyses, heuristic searches were performed with PAUP*. Heuristic searches were performed using the treebisection-reconnection (TBR) branch-swapping algorithm, and 10 and 100 replicates of a random-addition sequence for ML and MP, respectively. MP analyses were conducted with characters weighted in several ways (e.g., Maekawa et al., 1999): by equal weighing; by weighting TV two, four, and eight times Tl; and by excluding TI.

The confidence levels of each branch were estimated by 1000 bootstrap replications (Felsenstein, 1985) for the NJ analysis, 1000 bootstrap replications using heuristic searches with nearest-neighbor interchange (NNI) branch-swapping for the $\mathrm{ML}$ analysis, and 1000 bootstrap replications using heuristic searches with simple addition sequence and TBR branch swapping for the MP analysis. Decay indices (Bremer, 1988, 1994) were also estimated for the MP analysis.

Baysian phylogenetic analyses were conducted with MrBayes 3.0 (Huelsenbeck and Ronquist, 2001) under the general time reversible (GTR) model with the proportion of invariable sites and the gamma shape parameter $(G T R+I+\Gamma)$. Each Markov chain was started from a random tree and run for $5 \times 10^{5}$ generations, sampling the chains every 100th cycle. All sample points prior to reaching stationary (1000 trees) were discarded as burn-in samples. Data remaining after discarding burn-in samples were used to generate a majority-rule consensus tree, where the percentage of samples recovering any particular clade represented the clade's

Table 3. continued.

\begin{tabular}{|c|c|c|c|c|c|c|c|c|c|c|c|c|c|c|}
\hline & 14 & 15 & 16 & 17 & 18 & 19 & 20 & 21 & 22 & 23 & 24 & 25 & 26 & 27 \\
\hline \multicolumn{15}{|l|}{ 1. Dorcus curvidens binodulosus } \\
\hline \multicolumn{15}{|l|}{ 2. D. titanus pilifer } \\
\hline \multicolumn{15}{|l|}{ 3. D. titanus okinawanus } \\
\hline \multicolumn{15}{|l|}{ 4. D. r. rectus } \\
\hline \multicolumn{15}{|l|}{ 5. Rhaetulus recticornis } \\
\hline \multicolumn{15}{|l|}{ 6. Prosopocoilus i. inclinatus } \\
\hline \multicolumn{15}{|l|}{ 7. Pro. pseudodissimilis } \\
\hline \multicolumn{15}{|l|}{ 8. Prismognathus a. angularis } \\
\hline \multicolumn{15}{|l|}{ 9. Pri. dauricus } \\
\hline \multicolumn{15}{|l|}{ 10. Lucanus m. maculifemoratus } \\
\hline \multicolumn{15}{|l|}{ 11. L. ferriei } \\
\hline \multicolumn{15}{|l|}{ 12. Neolucanus $p$. protogenetivus } \\
\hline \multicolumn{15}{|l|}{ 13. Ne. protogenetivus hamaii } \\
\hline 14. Aegus laevicollis subnitidus & - & & & & & & & & & & & & & \\
\hline 15. Platycerus d. delicatulus & 23.4 & - & & & & & & & & & & & & \\
\hline 16. Pl. a. acticollis & 24.0 & 6.4 & - & & & & & & & & & & & \\
\hline 17. Figulus binodulus & 21.5 & 27.4 & 27.6 & - & & & & & & & & & & \\
\hline 18. F. boninensis & 23.6 & 28.5 & 27.9 & 7.9 & - & & & & & & & & & \\
\hline 19. Nigidius lewisi & 20.4 & 24.4 & 24.4 & 21.8 & 22.3 & - & & & & & & & & \\
\hline 20. Ceruchus I. lignarius & 23.3 & 23.0 & 21.5 & 26.6 & 27.8 & 26.0 & - & & & & & & & \\
\hline 21. Ce. I. monticola & 22.3 & 22.9 & 21.5 & 26.1 & 27.7 & 25.4 & 2.7 & - & & & & & & \\
\hline 22. Aesalus a. asiaticus & 26.5 & 22.5 & 22.9 & 28.8 & 29.5 & 25.1 & 23.4 & 23.1 & - & & & & & \\
\hline 23. Nicagus japonicus & 24.0 & 23.3 & 23.9 & 26.6 & 27.4 & 24.6 & 20.6 & 21.0 & 25.8 & - & & & & \\
\hline 24. Cylindrocaulus patalis & 27.0 & 27.2 & 26.6 & 27.9 & 29.5 & 26.1 & 26.3 & 26.3 & 28.4 & 25.8 & - & & & \\
\hline 25. Trypoxylus dichotomus septentrionalis & 22.6 & 21.3 & 19.8 & 23.8 & 24.5 & 22.6 & 22.7 & 22.7 & 26.1 & 23.4 & 21.8 & - & & \\
\hline 26. Heptophylla p. picea & 24.9 & 25.3 & 24.5 & 25.0 & 25.9 & 25.0 & 23.4 & 23.7 & 26.6 & 24.0 & 24.3 & 14.1 & - & \\
\hline 27. Trox uenoi & 23.2 & 21.2 & 21.2 & 24.4 & 25.8 & 22.4 & 21.9 & 21.7 & 23.6 & 19.8 & 21.1 & 14.8 & 17.4 & - \\
\hline 28. Geotrupes laevistriatus & 24.2 & 21.9 & 22.6 & 25.7 & 27.1 & 22.0 & 22.0 & 21.8 & 25.3 & 21.6 & 22.3 & 15.5 & 17.7 & 13.8 \\
\hline
\end{tabular}


posterior probability.

\section{Analysis of evolution of sexual dimorphism of mandibles}

To evaluate the degree of sexual dimorphism of mandibles in stag beetles, we used a scoring system with values of $0:$ no sexual dimorphism; 1: weak sexual dimorphism; and 2: strong sexual dimorphism (Fig. 1). These states were treated as ordered characters and mapped by parsimony optimization under accelerated transformation (ACCTRAN) and delayed transformation (DELTRAN) (Swofford and Maddison, 1987; Swofford and Olsen, 1990) using MacClade 4.0 (Maddison and Maddison, 2000).

\section{RESULTS}

\section{Sequence variation}

All sequences are deposited in DDBJ, EMBL and GenBank nucleotide sequence databases under accession numbers AB178292-AB178319 (Table 2). All sequences in the present study showed a substantial bias for adenine $(A)$ and thymine $(\mathrm{T})$ (average $=74.0 \%$ ). Several observations have demonstrated the existence of a strong AT bias in the insect mitochondrial genome (Simon et al., 1994).

Of the 1030 total aligned sites of the mitochondrial 16S rRNA gene fragment, 177 sites involved an insertion or deletion and were subsequently excluded from the analysis. In
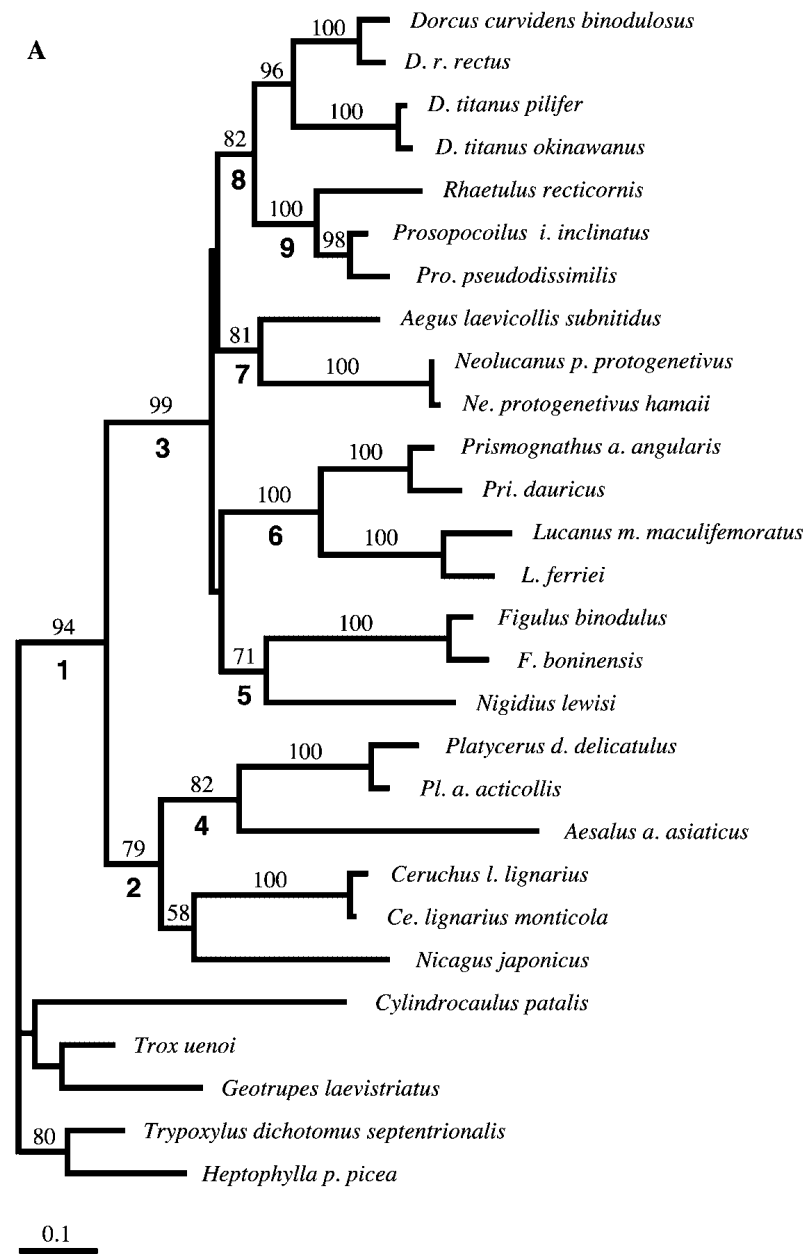

Fig. 4. To be continued.

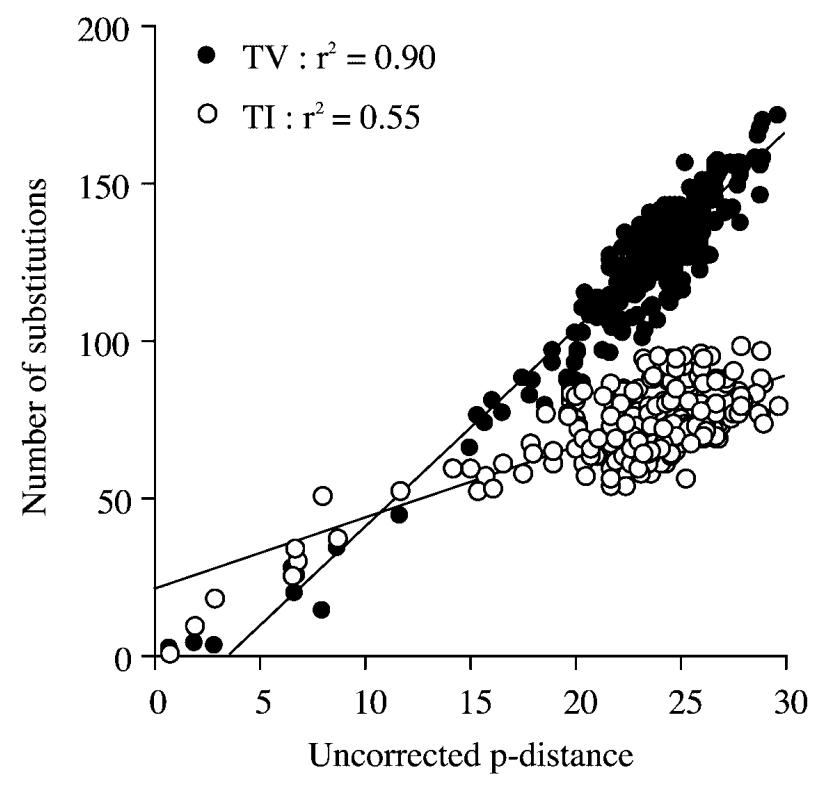

Fig. 3. Scatter plots showing the number of substitutions ( $\mathrm{TI}$ and TV) vs. uncorrected $p$ distance in the 16S rRNA gene sequence for pairwise comparisons among lucanid taxa. Closed and open circles represent TV and $\mathrm{TI}$, respectively. Squared regression coefficients (r) for each scatter-plot are also shown.

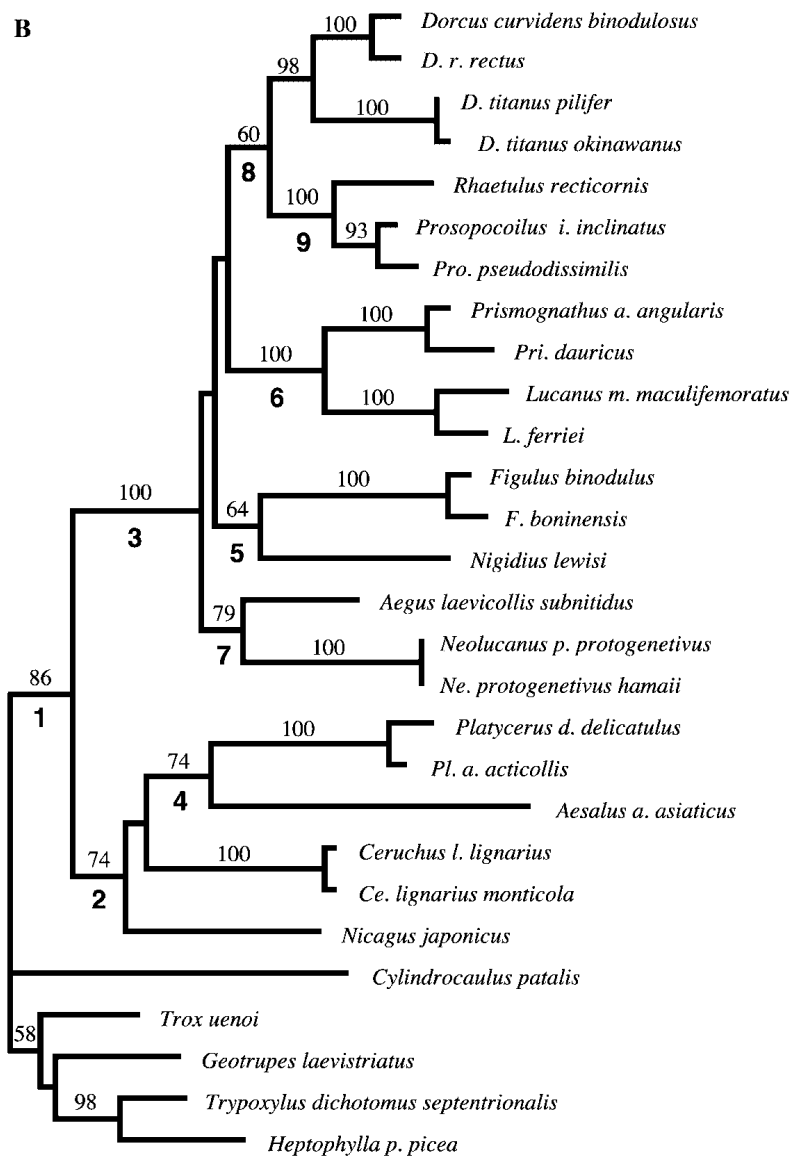

0.1 

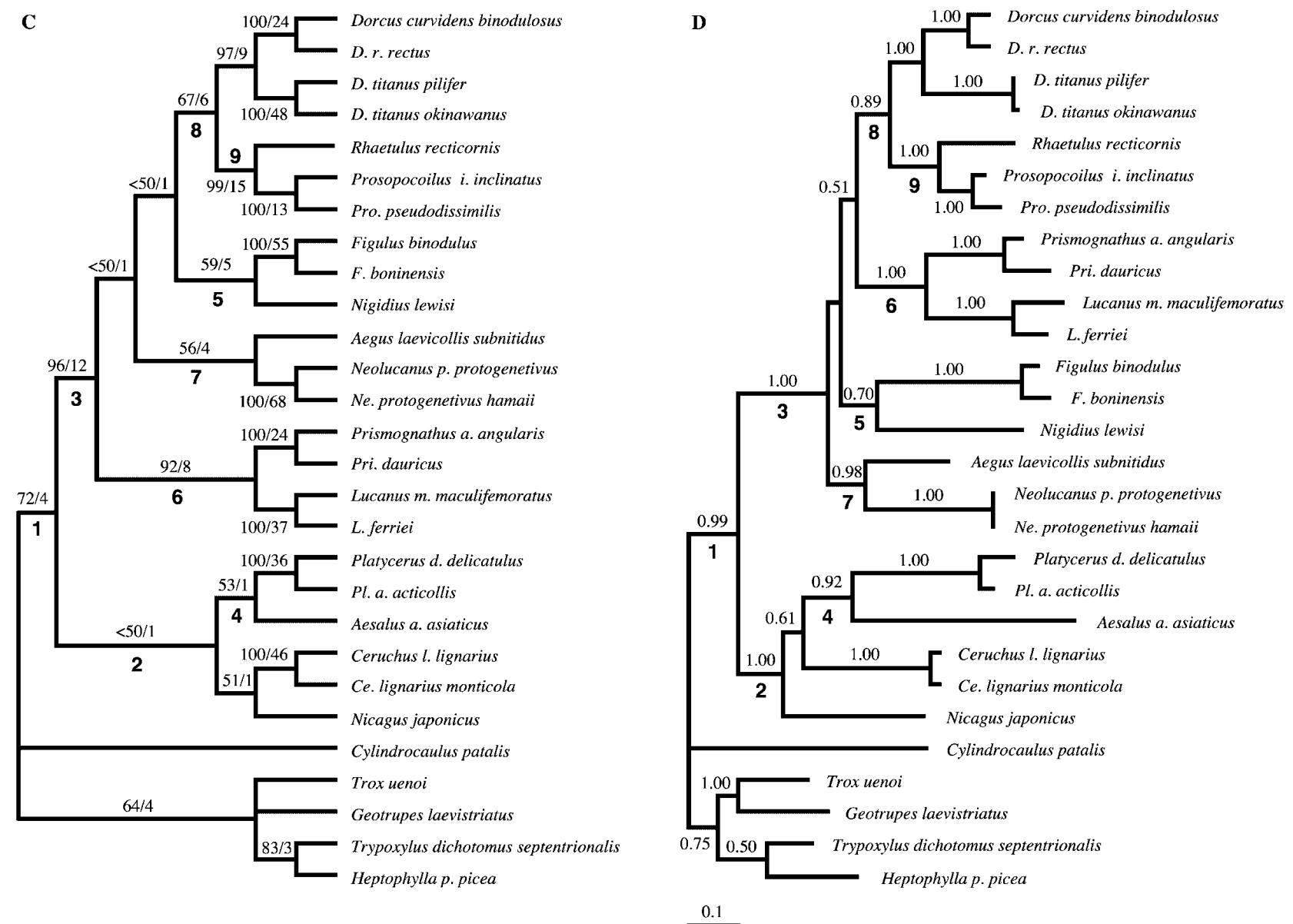

Fig. 4. A, Neighbor-joining (NJ) dendrogram derived from a distance matrix from the mitochondrial $16 \mathrm{~S}$ rRNA gene sequence. The numbers above internal branches represent the percentage of 1000 bootstrap replications that included the nodes. Nodes with bold numbers are identical with those in the ML and MP dendrograms below. Bar equals 0.1 substitutions/site. B, Maximum-likelihood (ML) dendrogram (In likelihood=-10234.21213). The numbers above internal branches represent the percentage of 1000 bootstrap replicates. Bar equals 0.1 substitutions/site. C, Strict consensus tree of two most parsimonious dendrograms resulting from non-weighted parsimony (MP) analysis (length $=2330$, consistency index $=0.39$, retention index $=0.52$, rescaled consistency index $=0.20$ ). Numbers above or below internal branches represent the percentage of 1000 bootstrap replicates and decay indices, respectively. D, Consensus tree inferred by Bayesian analysis. The numbers above or below internal branches represent the Bayesian posterior probabilities. Bar equals 0.1 substitutions/site.

the analyzed sites, 503 (59.0\%) were variable. Sequence divergence (uncorrected p-distance) is summarized in Table 3. Inter-subspecific nucleotide substitutions ranged from $0.6 \%$ (Ne. protogenetivus, insular subspecies collected on neighboring islands) to $2.7 \%$ (Ce. lignarius, mountainous subspecies collected on two mountains of the mainland of Japan). Inter-specific substitutions within the same genus ranged from $6.4 \%$ (Platycerus $d$. delicatulus vs. Pl. a. acuticollis) to $16.4 \%$ (D. curvidens binodulosus vs. D. titanus okinawanus). Nucleotide substitutions between genera within the family Lucanidae varied from $14.1 \%$ (Rhaetulus recticornis vs. Prosopocoilus i. inclinatus) to $29.5 \%$ (Figulus boninensis vs. Aesalus a. asiaticus), and those between Lucanidae and outgroups varied from 19.8\% (PI. a. acuticollis vs. Trypoxylus dichotomus septentrionalis, and Nicagus japonicus vs. Trox uenol) to $29.7 \%$ (R. recticornis vs. Cylindrocaulus patalis). The PTP test indicated a significant phylogenetic structure in the data set $(P=0.0001)$.
In a saturation analysis of the 16S rRNA gene of lucanid taxa (Fig. 3), the plot of TV vs. uncorrected p-distance was essentially linear $\left(r^{2}=0.90\right)$. However, the plot of $\mathrm{TI}$ suggests that slight saturation of $\mathrm{TI}$ may have occurred between certain pairs of taxa. Since multiple substitutions at a site can potentially obscure phylogenetic associations, the MP phylogenetic analysis was performed with four weighting schemes (weighting TV two, four, and eight times TI, and excluding $\mathrm{TI}$ ).

\section{Phylogenetic relationships}

Analysis of the 16S rRNA gene using MODELTEST supported two best-fit models of DNA substitution. The bestfit model for log-likelihood ratio tests was the general time reversible model (GTR) using five substitution types (Posada and Crandall [1998] called this the transversional model, or TVM), including the proportion of invariable sites (I) and the gamma distribution for rate variation among sites 
( $\Gamma)($ TVM $+I+\Gamma)$. The best fit model by the Akaike information criterion (Akaike, 1974) was the Tamura-Nei model with invariant sites and the gamma shape parameter $(\operatorname{TrN}+\mathrm{I}+$ $\Gamma)$. However, the two best-fit models were not congruent with each other. Of these, the more parameter-rich, GTR + $\mathrm{I}+\Gamma$, was used to estimate $\mathrm{ML}$ distances for a $\mathrm{NJ}$ analysis and to define parameters for a $\mathrm{ML}$ analysis. The base frequencies were approximately 0.3327 for $A, 0.0368$ for $C$, 0.1434 for $G$, and 0.4871 for $T$. Estimates of substitution rates were 0.7616 for $A-C, 4.7787$ for $A-G, 0.9542$ for $A-$ $\mathrm{T}, 0.1983$ for $\mathrm{C}-\mathrm{G}, 6.6954$ for $\mathrm{C}-\mathrm{T}$, and 1.0000 for $\mathrm{G}-\mathrm{T}$. The proportion of invariable sites and the gamma shape-distribution parameter were approximately 0.3453 and 0.8548 , respectively.

The NJ dendrogram using ML distance is shown in Fig. 4A. Following Hillis and Bull (1993), we considered a bootstrap proportion (BP) value $\geq 70 \%$ as a significant indicator of monophyly. In the NJ tree, conspecific and congeneric taxa clustered monophyletically, with high BP values (96$100 \%$ ). The monophyly of the family Lucanidae was supported by a BP of $94 \%$ (node 1). The lucanid ingroup in the $\mathrm{NJ}$ dendrogram comprised two clusters, one consisting of the genera Platycerus, Aesalus, Ceruchus, and Nicagus, supported by a BP of $79 \%$ (node 2), and the other including Dorcus, Rhaetulus, Prosopocoilus, Aegus, Neolucanus, Prismognathus, Lucanus, Figulus, and Nigidius, supported by a BP of $99 \%$ (node 3). In the former cluster, Platycerus and Aesalus form one cluster (node 4: BP $82 \%$ ). The latter cluster was split into four clusters. The first (node 5 ) consists of Figulus and Nigidius (BP 71\%); the second (node 6) includes Prismognathus and Lucanus (BP 100\%); the third (node 7) encompasses Aegus and Neolucanus (BP 81\%); and the fourth (node 8) contains Dorcus, Rhaetulus, and Prosopocoilus (BP 82\%). Node 8 was further split into a monotypic cluster of the genus Dorcus (BP 96\%) and a Rhaetulus-Prosopocoilus cluster (node 9, BP 100\%).

The topology of the ML dendrogram (Fig. 4B) was congruent with the $\mathrm{NJ}$ dendrogram with respect to nodes 1-9 at a BP level $\geq 70 \%$. Most nodes of the ML dendrogram were supported with BP values $\geq 70 \%$, with the only exception being a lower support level (BP 60-64\%) for nodes 5 and 8 .

The topology of the strict consensus dendrogram of two non-weighted MP trees (Fig. 4C) was congruent with the $\mathrm{NJ}$ dendrogram with respect to nodes $1-9$ at a BP level $\geq 70 \%$. Most nodes of the MP dendrogram were supported with BP values $\geq 70 \%$ (nodes $1,3,6$ and 9 ) or $50-69 \%$ (nodes 4,5 , 7 and 8 ), although a lower support level (BP $<50 \%$ ) was observed for node 2 .

MP trees resulting from four weighting schemes were all identical to one another in topology (data not shown). The dendrogram common to all the weighted MP analyses was congruent with the strict consensus dendrogram from the non-weighted MP analysis, except for the absence of node 2 in the former. Most nodes were supported with BP values $\geq 50 \%$ for both the non-weighted (Fig. 4C: nodes 1 and 3-9) and weighted MP dendrograms, although there was lower support $(\mathrm{BP}<50 \%)$ for node 8 in weighted MP trees that excluded TI.

The topology of the consensus dendrogram from the Bayesian analysis (Fig. 4D) was congruent with the $\mathrm{NJ}$ dendrogram with respect to nodes $1-9$ at a BP level $\geq 70 \%$. Most nodes of the Bayesian dendrogram were supported with posterior probability (PP) values $\geq 0.90$, except for a lower support level (PP 0.70-0.89) for nodes 5 and 8.

\section{Reconstructing ancestral character states of sexual dimorphism of mandible shape}

The Bayesian tree topology (Fig. 4D) was used in MacClade to trace minimum sexual dimorphism grade shifts. This is identical to the ML ingroup topology (Fig. 4B). Character tracing with parsimony optimization is shown in Fig. 5 . These reconstructions required six steps.

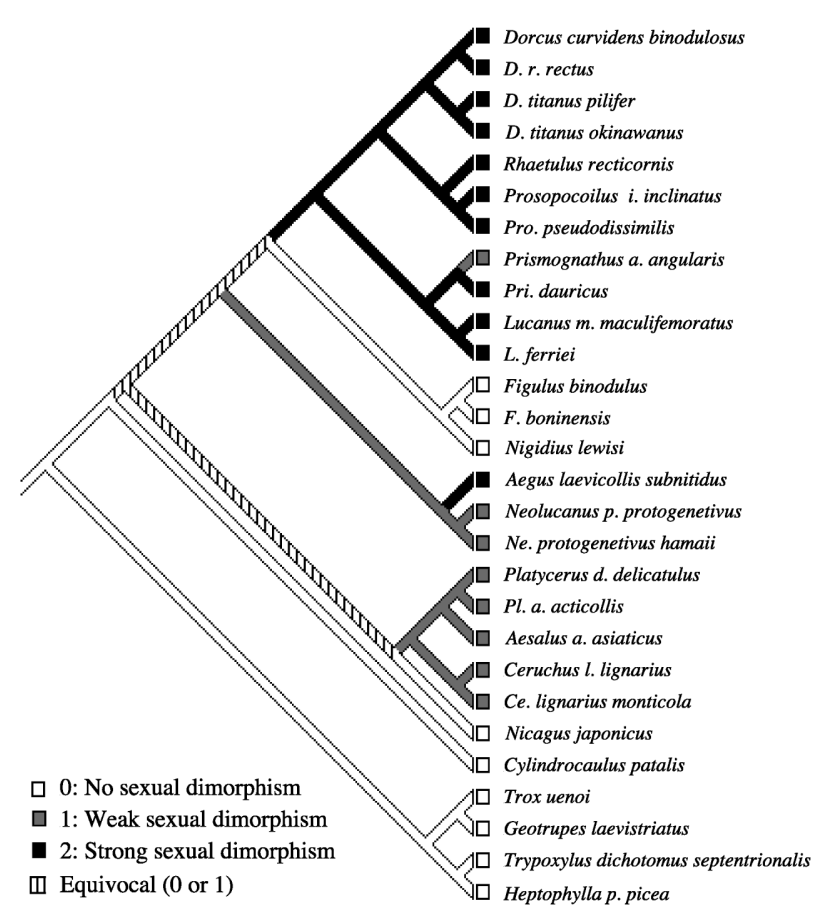

Fig. 5. Parsimony optimization of sexual dimorphism in mandible shape on a phylogenetic estimation based on the tree inferred by Bayesian analysis.

\section{DISCUSSION}

\section{Sequence divergence of Lucanidae}

Among the three species selected with two subspecies pairs each, inter-subspecific nucleotide substitution of $\mathrm{Ce}$. lignarius $(2.7 \%)$ collected from mountains of the mainland of Japan was roughly twice than that of $D$. titanus $(1.8 \%)$ collected from mainland Japan and the Ryukyu archipelago. The relatively larger inter-subspecific nucleotide substitution of $\mathrm{Ce}$. lignarius suggests that this species strongly reflects the geohistory of the Japanese islands, because its distribution is restricted to mountainous areas. 
In this study, sequence differentiation increased in the order of inter-subspecies (0.6-2.7\%), interspecies (6.4$16.4 \%)$, and inter-genera (14.1-29.5\%). Additionally, nodes containing all taxa included for a species or for a genus were supported with high BP values (96-100\% in NJ; 93$100 \%$ in ML; $97-100 \%$ in non-weighted MP) and Bayesian PP values (1.00). The results of the PTP test also indicate that the 16S rRNA data set has significant phylogenetic structure. All of the weighted MP analyses were congruent with the strict consensus tree from the non-weighted MP analysis. These results suggest that saturation of $\mathrm{TI}$ was slight, and that the 16S rRNA gene was a good molecule with which to infer the phylogeny of the lucanids used in this study.

\section{Phylogenetic relationships of Lucanidae}

The molecular phylogeny presented herein provides a robust framework in which to evaluate previous taxonomic schemes relating to the family Lucanidae. Our study suggests that the family Lucanidae occurring in Japan is monophyletic (node 1). This result contradicts placement of the genus Nicagus in the family Trogidae (Nomura, 1960; Kurosawa, 1976; Kikuta, 1986, see Table 1). On the basis of adult and larval morphological characters, Tabana and Okuda (1992) suggested that Nicagus belongs to Lucanidae, rather than Trogidae. Browne and Scholtz (1999) also indicated the monophyly of Lucanidae and inclusion of Nicagus, on the basis of nine synapomorphies inferred from a cladistic analysis of mainly adult characters.

Our phylogenetic tree shows that the family Lucanidae contains two lineages: an "ancestral cluster" (node 2) consisting of morphologically ancestral genera (Arrow, 1950), and a "true lucanid cluster" (node 3 ) that includes species with well developed mandibles in males. The former lineage indicates the monophyly of the subfamily Aesalinae sensu Benesh (1960) and Krajcik (2001), including Platycerus, Aesalus, Ceruchus, and Nicagus. The "ancestral cluster" also indicates non-monophyly of Aesalus and Nicagus, which contradicts the treatment of Maes (1992) that suggested Aesalus and Nicagus are closely related.

Only two lucanid fossils are known from the Mesozoic era: Paralucanus mesozoicus, the older one, from the upper Jurassic of Mongolia (Nikolajev, 2000), and Cretaesalus ponomarenkoi from the upper Cretaceous of Kazakhstan (Nikolajev, 1993). Of these, Cretaesalus ponomarenkoi is allied to the genus Aesalus of the "ancestral cluster" discussed above. The oldest lucanid fossils considered as belonging to the "true lucanid cluster" are from the Eocene (Krell, 2000). The fossil data suggest that the "ancestral cluster" contains both morphologically and paleontologically ancestral genera that may have already diverged in the Mesozoic or early Tertiary.

Hayashi (1992) suggested on the basis of morphology that Figulus and Nigidius, which are relatively small in body size and non-sexually dimorphic, are the most ancestral genera. In our results, however, these genera are included in the "true lucanid cluster" (node 3 ), as is the tribe Lucanini sensu Kikuta (1986) that includes genera such as Dorcus, Rhaetulus, Prosopocoilus, Aegus, Neolucanus, Prismognathus, and Lucanus. Gokan et al. (1998) also suggested a close affinity of Figulus to genera within the "true lucanid cluster" on the basis of the structural organization of the compound eyes; Figulus shares a similar eye structure with Lucanus, but not with Platycerus or Aesalus. According to Kikuta (1986), a "true lucanid cluster", equivalent to that revealed in the present study, is defined by the following adult characters: second antennal segment more or less long and cylindrical, jointed at the apical upper angle of the first segment, antennae geniculate; labrum fused with clypeus and indistinct; eyes with canthus; and metepisternum distant from the mesocoxal cavity.

Unfortunately, our results cannot shed light on the phylogenetic relationships between the tribes Figulini and Lucanini sensu Kikuta (1986), nor do they clearly support the monophyly of the tribe Lucanini sensu Kikuta (1986). In our study, the tribe Lucanini sensu Kikuta (1986) is split into three subclusters: a Lucanus-Prismognathus cluster (node 6), an Aegus-Neolucanus cluster (node 7), and a DorcusRhaetulus-Prosopocoilus cluster (node 8). Our results do not agree with previous higher classification systems such as those proposed by Didier and Séguy (1953), Benesh (1960), Maes (1992) and Krajcik (2001), or with the hypothetical phylogram of Houlbert (1915). Further study is needed to clarify these phylogenetic associations.

To our surprise, in our results Neolucanus and Aegus form one cluster (node 7), which contradicts previous taxonomic systems (Table 1). On the other hand, our results do not support close phylogenetic affinities of Neolucanus and Lucanus, and of the Aegus with other genera of Dorcinae, as suggested by Benesh (1960), Maes (1992), and Krajcik (2001). An analysis of ecological characteristics (Araya, 1994) also suggests a closer relationship between Neolucanus and Aegus. The larvae of both Neolucanus and Aegus are found in detritus or humus, indicating an association with the activity of termites, whereas other genera of the "true lucanid cluster" are mainly found in dead wood with white rot.

Arrow (1950) lumped many genera into the single genus Dorcus, including Prosopocoilus, Prismognathus, and Rhaetulus and its allied genera. Our previous study based on nucleotide sequences of the mitochondrial $\mathrm{COI}$ gene (Hosoya et al., 2003) did not clearly resolve the phylogenetic relationships among Dorcus, Prosopocoilus, and Prismognathus. Our present results indicate the monophyly of Dorcus, with the exception that Prismognathus (node 8) shows greater affinity with Lucanus (node 6). These results agree with the affinities that Hayashi (1956) suggested on the basis of similarity between the larval characters Prismognathus and Lucanus, and that Kikuta (1986) suggested on the basis of adult characters.

Our study indicates that Rhaetulus is more closely related to Prosopocoilus than to Lucanus or Dorcus (node 
9). This result contradicts the previously proposed taxonomic position of Rhaetulus, which had been suggested to have a closer relationship with Lucanus (Didier and Séguy, 1953) or Dorcus (Kikuta, 1986). Our result instead supports the suggestion of Maes (1992) that Rhaetulus belongs to the tribe Cladgnathini, which also includes Prosopocoilus.

\section{Evolution of the sexual dimorphism of mandible shape}

Stag beetles show remarkable sexual dimorphism, especially in the shape of the mandibles, and display variation in the degree of development of this dimorphism. The exaggerated mandible is found only in the males (Arrow, 1937), with mandibles being used mainly for fighting between conspecific males (Mathieu, 1969; Hayashi, 1987). Males having well-developed mandibles are at a selective advantage during male-male combat because such mandibles help them to secure beneficial habitats and/or females for mating (Morimoto, 1986; Ichikawa, 1986; Hayashi, 1987; Shiokawa and Iwahashi, 2000).

Our result (Fig. 5) indicates that strong sexual dimorphism with well-developed mandibles in males evolved independently at least twice, once in the genus Aegus and once in the ancestor of the Lucanus-Prismognathus and the Dorcus-Rhaetulus-Prosopocoilus clusters, and furthermore that this sexual dimorphism was secondarily weakened in Prismognathus a. angularis. Males of species with strong sexual dimorphism of the mandibles engage in combat with conspecific males, mainly in open habitats such as the sap on trees, by holding and throwing competitors using their mandibles (Ichikawa, 1986; Hayashi, 1987; Okajima and Yamaguchi, 1988; Shiokawa and Iwahashi, 2000). Therefore, well-developed mandibles in males of these species should evolve if the advantages of winning a fight confer greater reproductive success.

Weak sexual dimorphism of mandibles in males is found in Prismognathus a. angularis and the genera Neolucanus, Platycerus, Aesalus, and Ceruchus. Males of Prismognathus a. angularis and Neolucanus do not inhabit the sap regions of trees (Okajima and Yamaguchi, 1988), but wait and guard females for mating at oviposition sites, such as in hollows of trees (Okajima and Yamaguchi, 1988; Araya and Ôbuchi, 1992). Males of Platycerus, Aesalus, and Ceruchus also guard females at oviposition sites, such as narrow tunnels dug into decayed wood or under logs (e.g., Araya, 1989). In summary, species that retain weak sexual dimorphism of mandibles in males, or as in Prismognathus a. angularis show a shift from strong to weak sexual dimorphism in the mandibles, do not engage in combat in open habitats, but rather in relatively narrow spaces.

Our results suggest that either the lucanid ancestor possessed weak sexual dimorphism of the mandibles, or that absence of sexual dimorphism of the mandibles is the ancestral character state. The result of our ACCTRAN character optimization, which places character transformations closer to the root of the cladogram, indicated the possibility that sexual dimorphism in mandible shape was secondarily lost at least twice, once in the genus Nicagus and once in the Figulus-Nigidius cluster. Adults and larvae of Figulus and Nigidius live within decayed wood in colonies that are composed of male-female pairs (monogamy), just as with species of the family Passalidae, which show subsocial behavior (Araya et al., 1996) and in which the two sexes are of identical form. Males of Nicagus do not engage in combat or guard females (Tabana and Okuda, 1992; Katovich and Kriska, 2002). Additionally, a developmental cost is inevitable in producing exaggerated and elongated mandibles (Kawano, 1997; Tatsuta et al., 2001). Therefore, if the lucanid ancestor possessed weak sexual dimorphism, as indicated by our ACCTRAN result, these genera appear to have lost sexual dimorphism in the mandible shape.

The result of our DELTRAN character optimization, which places character transformations far from the root of the cladogram, indicated that the lucanid ancestor was not sexually dimorphic in the mandible. This analysis suggested that the genera Nicagus, Figulus, and Nigidius have retained the ancestral character state, and that sexual dimorphism of mandibles evolved independently at least three times, once among members of the Ceruchus, Platycerus, and Aesalus cluster, once in the Aegus and Neolucanus cluster, and once in the Dorcus, Rhaetulus, Prosopoilus, Prismognathus, and Lucanus cluster. If the lucanid ancestor was not sexually dimorphic, these genera appear to have evolved sexual dimorphism in the mandibles for combat with conspecific males in open habitats or in relatively narrow spaces.

Our study treated the phylogenetic relationships among the main lineages of the family Lucanidae from Japan, and the evolution of sexual dimorphism in the shape of the mandibles within the family. Unfortunately, however, we could not include taxa of several subfamilies and tribes in this study. Further analyses including representatives of these taxa will be necessary to fully reveal phylogenetic relationships and the evolution of the sexual dimorphism within the Lucanidae.

\section{ACKNOWLEDGMENTS}

We thank A. Abe and M. Kon for providing materials and literature and for offering valuable advice; S. Osawa, M. Matsui, T. Hikida, H. Shima, O. Yata, T. Yagi, Z. -H. Su, C.-G. Kim, and M. Honda for various kinds of help; T. Sota and M. Toda for critical reading of the manuscript; and K. Wada, Y. Maeda, and T. Yamada for providing us with materials. We also thank K. Nakamura, N. Nakagawa, K. Iwata, and Y. Shimamura for their assistance in sample collection. This study was partially supported by Grants-in-Aid from the Ministry of Education, Science, Sports, and Culture of Japan (Nos. 09839030 and 11833007 to K. A.).

\section{REFERENCES}

Akaike $\mathrm{H}$ (1974) A new look at the statistical model identification. IEEE Trans Autom Contr 19: 716-723

Araya K (1989) Oviposition behavior of Japanese lucanid beetles (Coleoptera). Nature and Insects 24(10): 6-14 (In Japanese)

Araya K (1994) On the habitat of lucanid larvae (Coleoptera, 
Lucanidae) in Southeast Asia. Nature and Insects 29(2): 2-10 (In Japanese)

Araya K, Ôbuchi T (1992) Life histories of Japanese lucanid beetles (Coleoptera: Lucanidae). 2) Prismognathus angularis Waterhouse. Nature and Insects 27(9): 24-32 (In Japanese with English summary)

Araya K, Kon M, Ueda A (1996) Subsociality in wood-eating beetles. In "Evolutionary ecology of kin relations. Social in Arthropoda" Ed by Y Saito, Hokkaido Univ. Press, Sapporo, pp 76108 (In Japanese)

Arrow GJ (1937) Dimorphism in the males of stag-beetles (Coleoptera, Lucanidae). Trans R Ent Soc Lond 86: 239-245

Arrow GJ (1950) The fauna of India including Pakistan, Ceylon, Burma and Malaya. Coleoptera, Lamellicornia, Vol. IV. Lucanidae and Passalidae. Taylor and Francis, London

Benesh B (1960) Lucanidae, 2nd ed. Coleopterorum Catalogus, Supplementa 8, Dr. W. Junk, Den Haag, 178 pp

Bremer K (1988) The limits of amino acid sequence data in angiosperm phylogenetic reconstruction. Evolution 42: 795803

Bremer K (1994) Branch support and tree stability. Cladistics 10: 295-304

Browne J, Scholtz CH (1999) A phylogeny of the families of Scarabaeoidea (Coleoptera). Syst Entomol 24: 51-84

Clary DO, Wolstenholme DR (1985) The mitochondrial DNA molecule of Drosophila yakuba: nucleotide sequence, gene organization, and genetic code. J Mol Evol 22: 252-271

Didier R, Séguy E (1953) Catalogue illustré des Lucanides du globe. Texte. Encyc Entom (A) 27: 1-223

Dowton M, Austin AD (1994) Molecular phylogeny of the insect order Hymenoptera: apocritan relationships. Proc Natl Acad Sci USA 91: 9911-9915

Faith DP, Cranston PS (1991) Could a cladogram this short have arisen by chance alone? : On permutation tests for cladistic structure. Cladistics 7: 1-28

Fang Q, Black IV WC, Blocker HD, Whitcomb RF (1993) A phylogeny of new world Deltocephalus-like leafhopper genera based on mitochondrial $16 \mathrm{~S}$ ribosomal DNA sequences. Mol Biol Evol 2: $119-131$

Felsenstein J (1985) Confidence limits on phylogenies: an approach using the bootstrap. Evolution 39: 783-791

Gokan N, Meyer-Rochow VB, Nakazawa A, lida K (1998) Compound eye ultrastructures in six species of ecologically diverse stag-beetles (Coleoptera, Scarabaeoidea, Lucanidae). Appl Entomol Zool 33: 157-169

Han H-Y, McPheron BA (1997) Molecular phylogenetic study of Tephritidae (Insecta: Diptera) using partial sequences of the mitochondrial 16S ribosomal DNA. Mol Biol Evol 7: 17-32

Hayashi N (1956) Morphology of immature-stage of Japanese Lucanidae (studies on Coleopterous larvae IV). New Entmol 5(4): 10-13 (In Japanese with English summary)

Hayashi N (1987) Lucanus maculifemoratus. The insects of Japan. Series 8. Bun-ichi Sogo, Tokyo (In Japanese)

Hayashi N (1992) The mandibles used in fighting. Stag beetle. In "The earth of the animals Vol 3 Insect" Ed by K Morimoto, Asahi-shinbun, Tokyo, pp 199-201 (In Japanese)

Hillis DM, Bull JJ (1993) An empirical test of bootstrapping as a method for assessing confidence in phylogenetic analysis. Syst Biol 42: 182-192

Hosoya T, Honda M, Araya K (2001) Genetic variations of $16 \mathrm{~S}$ rRNA gene observed in Ceruchus lignarius and Dorcus rectus rectus (Coleoptera: Lucanidae). Entomol Sci 4: 335-344

Hosoya T, Araya K, Shirota Y (2002) Molecular phylogeny of Japanese and Taiwanese stag beetles of the genus Dorcus and its allied genera (Coleoptera, Lucanidae) based on random amplified polymorphic DNA. G Ital Entomol 10: 133-140

Hosoya T, Araya K, Shirota Y (2003) Molecular phylogeny of Japa- nese stag beetles of the genus Dorcus (Coleoptera: Lucanidae) and its allied genera inferred from mitochondrial $\mathrm{COI}$ gene sequences. Elytra 31: 127-142

Houlbert C (1915) La loi de la taille et l'évolution des Coléoptères. Insecta 5: 5-11

Huelsenbeck JP, Ronquist F (2001) MrBayes: Bayesian inference of phylogeny. Bioinformatics 17: 754-755

Huxley JS (1931) Relative growth of mandibles in stag-beetles (Lucanidae). J Linn Soc (Zool) 37: 675-703

Ichikawa T (1986) Notes on the Dorcus curvidens group (Coleoptera, Lucanidae) from Japan and the Southeast Asia. Gekkan-Mushi 185: 4-12 (In Japanese)

Igarashi S, Matsuoka N, Abe A (1994) Allozyme study on the phylogenetic relationships among three species of stag beetles of the family Lucanidae (Coleoptera). Sci Rep Hirosaki Univ 41: 215-221 (In Japanese with English summary)

Ikeda K, Nishimura M (1995) The rediscovery of Dorcus grandis Didier from Laos. Gekkan-Mushi 292: 17-21 (In Japanese with English summary)

Inukai T (1924) Statistical studies on the variation of stagbeetles. Trans Sapporo Nat Hist Soc 9: 77-91

Kambhampati S, Kjer KM, Thorne BL (1996) Phylogenetic relationship among termite families based on DNA sequence of mitochondrial 16S ribosomal RNA gene. Insect Mol Biol 5: 229-238

Kambhampati S, Völkl W, Mackauer M (2000) Phylogenetic relationships among genera of Aphidiinae (Hymenoptera: Braconidae) based on DNA sequence of the mitochondrial $16 \mathrm{~S}$ rRNA gene. Syst Entomol 25: 437-445

Katovich K, Kriska NL (2002) Description of the larva of Nicagus obscurus (LeConte) (Coleoptera: Lucanidae: Nicaginae), with comments on its position in Lucanidae and notes adult habitat. Coleopt Bull 56: 253-258

Kawano K (1997) Cost of evolving exaggerated mandibles in stag beetles (Coleoptera: Lucanidae). Ann Entomol Soc Am 90: $453-461$

Kawano K (2000) Genera and allometry in the stag beetle family Lucanidae, Coleoptera. Ann Entomol Soc Am 93: 198-207

Kikuta T (1986) On the higher taxa of the stag beetle family Lucanidae. Spcl Bull Jap Soc Coleopt 2: 131-138

Krajcik M (2001) Lucanidae of the world, Catalogue Part I. Checklist of the stag beetles of the world (Coleoptera: Lucanidae), Milan Krajcik, Czech

Krell FT (2000) The fossil record of Mesozoic and Tertiary Scarabaeoidea (Coleoptera: Polyphaga). Invert Taxon 14: 871-905

Kurosawa Y (1976) Family Lucanidae. Check-list of Coleoptera of Japan 1, The Coleopterists' Association of Japan, Tokyo, pp 1-9 (In Japanese)

Maddison DR, Maddison WP (2000) MacClade 4: Analysis of Phylogeny and Character Evolution (version 4), Sinauer, Sunderland

Maekawa K, Matsumoto T (2000) Molecular phylogeny of cockroaches (blattaria) based on mitochondrial cOll gene sequences. Syst Entomol 25: 511-519

Maekawa K, Lo N, Kitade O, Miura T, Matsumoto T (1999) Molecular phylogeny and geographic distribution of wood-feeding cockroaches in East Asian islands. Mol Phylogenet Evol 13: 360-376

Maes J-M (1992) Lista de los Lucanidae (Coleoptera) del mundo. Revista Nicarag Ent 22: 1-121

Mathieu JM (1969) Mating behavior of five species of Lucanidae (Coleoptera: Insecta). Can Ent 101: 1054-1062

Matsuoka N, Hosoya T (2003) Molecular phylogeny of Japanese Stag-beetles. Bull Fac Agric Life Sci Hirosaki Univ 5: 9-16 (In Japanese with English summary)

Matsuoka N, Hosoya T, Hamaya T, Abe A (1998) Phylogenetic relationships among four species of stag beetles (Coleoptera: Lucanidae) based on allozymes. Comp Biochem Physiol 119B: 


$$
401-406
$$

Mizunuma T, Nagai S (1994) The lucanid beetles of the world. In "Mushi sha's iconographic series of insects 1" Ed by H Fujita, Mushi-Sha, Tokyo (In Japanese with English summary)

Morimoto K (1986) Horns of Dynastes and mandibles of Lucanidae. In "The Coleoptera of Japan in color Vol 1" Ed by K Morimoto and N Hayashi, Hoikusha, Osaka, pp 134-135 (In Japanese)

Nikolajev GV (1993) Nakhodka grebenchatousogo zhuka (Coleoptera, Lucanidae) v verkhnem mele Kazahstana. Selevinia 1993(1): 89-92

Nikolajev GV (2000) New subfamily of the stag beetles (Coleoptera: Scarabaeoidea: Lucanidae) from the Mesozoic of Mongolia, and its position in the system of the superfamily. Paleontol $\mathrm{J} 34$ Suppl 3: S327-S330

Nomura S (1960) List of the Japanese Scarabaeoidea (Coleoptera), (Notes on the Japanese Scarabaeoidea. II.). Tôhô Gakuhô 10: 39-79 (In Japanese with English summary)

Okajima S, Yamaguchi S (1988) The Stag Beetles. Hoiku-sya, Osaka (In Japanese)

Otte D, Stayman K (1979) Beetle horns: some patterns in functional morphology. In "Sexual selection and reproductive competition in insects" Ed by M Blum and N Blum, Academic Press, New York, pp 259-292

Posada D, Crandall KA (1998) MODELTEST: testing the model of DNA substitution. Bioinfomatics 14: 817-818

Saiki RK, Gelfand DH, Stoffel S, Higuchi R, Horn GT, Mullis KB, Erlich HA (1988) Primer-directed enzymatic amplification of DNA with a thermostable DNA polymerase. Science 239: 487491

Sakaino H (1987) Polymorphism in the stag-beetles, and its constructions. I. Gekkan-Mushi 187: 16-20 (In Japanese)

Sakaino H (1988) Polymorphism in the stag-beetles, and its constructions. II. Gekkan-Mushi 203: 17-25 (In Japanese)
Sharp D, Muir F (1912) The comparative anatomy of the male genital tube in Coleoptera. Trans R Ent Soc Lond 3: 477-642

Simon C, Frati F, Beckenbach A, Crespi B, Liu H, Frook P (1994) Evolution, weighting and phylogenetic utility of mitochondrial gene sequences and a compilation of conserved polymerase chain reaction primers. Ann Entomol Soc Am 87: 651-701

Shiokawa T, Iwahashi O (2000) Mating success of small sized males of Japanese stag beetle Prosopocoilus dissimilis okinawanus Nomura. Jpn J Ent (N.S.) 3: 157-165 (In Japanese with English summary)

Swofford DL (2002) PAUP*: Phylogenetic Analysis Using Parsimony ( ${ }^{*}$ and Other Methods), version 4.0b10. Sinauer Associates, Sunderland

Swofford DL, Maddison WP (1987) Reconstructing ancestral character states under Wagner parsimony. Math Biosci 87: 199229

Swofford DL, Olsen GJ (1990) Phylogeny reconstraction. In "Molecular systematics" Ed by DM Hillis and C Moritz, Sinauer Associates, Sunderland, pp 411-501

Tabana M, Okuda N (1992) Notes on Nicagus japonicus Nagel. Gekkan-Mushi 292: 17-21 (In Japanese with English summary)

Tatsuta H, Mizota K, Akimoto S (2001) Allometric patterns of Head and genitalia in the stag beetle Lucanus maculifemoratus (Coleoptera: Lucanidae). Ann Entomol Soc Am 94: 462-466

Thompson JD, Higgins DG, Gibson, TJ (1994) Clustal W: improving the sensitivity of progressive multiple sequence alignment through sequence weighting, position specific gap penalties and weight matrix choice. Nucl Acids Res 22: 4673-4680

Trewick SA (2000) Molecular evidence for dispersal rather than vicariance as the origin of flightless insect species on the Chatham Islands, New Zealand. J Biogeogr 27: 1189-1200

(Received July 7, 2005 / Accepted October 7, 2005) 